\title{
Los cervantistas mallorquines: apuntes sobre la recepción crítica y las traducciones del Quijote al mallorquín
}

\author{
Luisa Cotoner Cerdó*
}

A partir de los datos que ofrece el estudio de Francesc Carreras i Candi Lo cervantismo a Barcelona, ${ }^{1}$ resulta inevitable pensar que el cervantismo, tal y como lo entendemos hoy, es un invento del siglo XIX. La llamada por el erudito catalán «mania cervàntica» se materializa entonces en Cataluña - lo mismo que en el resto de España- en toda suerte de empresas relacionadas con Cervantes o con el Quijote. Proliferan las ediciones y estampaciones, los trabajos eruditos, se reúnen importantes colecciones cervantinas, entre las que destaca la de Isidro Bonsoms, se funda la «Societat lírico-dramàtica Cervantes», se acuñan medallas y toda suerte de bagatelas alusivas a temas y personajes cervantinos, y aparecen también las primeras traducciones al catalán, como homenaje, pero a la vez como banco de pruebas para demostrar la capacidad de una lengua sobre la que se cernía la amenaza de quedar relegada a círculos particulares.

En tal ambiente, no puede extrañarnos que también en las Baleares y, concretamente, en Mallorca el fervor cervantino haga acto de presencia, sobre todo, en las celebraciones organizadas a propósito del Tercer Centenario de la aparición del Quijote y que personalidades tan relevantes como Joan Alcover, Ildefonso Rullán, Miquel dels Sants Oliver o Gabriel Alomar contribuyan a su

*. Universitat de Vic.

1. CARreras y CAndi, Francesch, Lo cervantisme a Barcelona, Barcelona, Estampa "La Catalana" de J. Puigventós, 1895. 
estudio con una serie de notables aportaciones. Por otra parte, el interés de los mallorquines por Cervantes no se agota en aquel periodo excepcional, continúa a lo largo del siglo XX y llega hasta hoy para reaparecer con renovada pujanza en las conmemoraciones de 2005.

Quizás valga la pena detenerser en los trabajos que resultan más representativos por una u otra causa, ya que, a mi modesto entender, bien merecen un poco más de atención de la que, en general, se les ha dispensado.

Indudablemente, en los primeros años del siglo XX, el cervantismo mallorquín se encuadra en la etiqueta acuñada por Carreres i Candi, aunque no es menos cierto que la devoción cervantina en el antiguo reino de Mallorca adquiere también características propias. Destacan dos: la primera, la unanimidad de criterio que los escritores isleños mostraron a favor de la celebración del centenario en 1905; y la segunda, más llamativa aún, la peculiar manera que tienen los traductores mallorquines de apropiarse del Quijote hasta extremos inusitados en comparación con el resto de las versiones al catalán.

Respecto a la primera, de los documentos que he consultado se deduce que entre la intelectualidad mallorquina no se desataron polémicas en torno a la celebración. Incluso puede asegurarse que se aceptó de buen grado, muy al contrario de lo sucedido en Cataluña, donde se produjo una auténtica fractura entre partidarios y detractores de la conmemoración. ${ }^{2}$ Es más, algunos polígrafos mallorquines entraron en la liza barcelonesa para justificar el homenaje cervantófilo desde diferentes enfoques.

En ese sentido, una de las piezas que ponen de manifiesto lo alejados que estaban los mallorquines de litigios estériles, es el discurso que el poeta Joan Alcover — uno de los padres de la Escola Mallorquina y artífice del resurgimiento del catalán como lengua de cultura - pronunció en el Teatro Principal de Palma en aquella ocasión. ${ }^{3}$ Alcover, tras rechazar manipulaciones espurias - se refiere obviamente a las interpretaciones casticistas, que reducen el Quijote a «servir de valedor en pro de los públicos intereses, por altos y sagrados que fuesen»-, manifiesta que el Centenario debería aprovecharse para acrecentar el entusiasmo e «iluminar y reanimar a España». ${ }^{4}$ Se declara sin ambages, admirador de la obra ${ }^{5}$ y de su autor, un «coloso» solo comparable a Homero y Shakespeare, si bien añade que «Cervantes hizo más» puesto que, si

2. Como veremos más adelante, la repercusión en la prensa barcelonesa de esa polémica ha sido pormenorizadamente estudiada por la escritora mallorquina Carme Riera (véanse notas 66 y 69 ).

3. El discurso, pronunciado en castellano, se publicó en el periódico palmesano La Almudaina y en la revista Catalunya. Cito por esta última, Alcover, Joan, «Discurs de don..., Llegit al Teatre Principal de Palma», Catalunya. Revista quinzenal, XXX, maig de 1905, pp. 14-23. (Aunque el título aparezca traducido, el texto está en la lengua original).

4. Y apostilla: «Importa, pues, a nuestro egoísmo patriótico, sacar el jugo a este grande asunto, aprovecharnos de su íntima virtualidad si acertamos a comprenderla, abrazarnos a él amorosamente, a ver si nos calienta y desentumece, que bien lo necesitamos» (AlCover, Joan, Ibíd. p. 15).

5. Alcover demuestra el profundo conocimiento que tenía del Quijote y de las diferentes interpretaciones que en esa época suscitaba la obra. 
aquellos «apenas inventaron», éste «puso de su parte la originalidad más estupenda, los mayores prodigios de invención que ha realizado jamás la humana fantasía.» ${ }^{6}$ De hecho, toda la última parte de su discurso — salpicada de alusiones a obras como el Viaje del Parnaso o el Persiles, popularmente poco conocidas-, gira en torno a la vida de Cervantes, a quien considera un ejemplo de dignidad moral y se congratula de que «la memoria de Cervantes» se mantenga a salvo, ya fueran justos o injustos los procesos incoados contra su persona. $^{7}$

De sus palabras se deduce que Alcover siente como propio el legado cervantino, sin que ello le suponga en modo alguno renunciar a la recuperación de la tradición literaria y cultural autóctona. ${ }^{8}$

Esta postura coincide en lo esencial con la que, por su parte, adoptaron los dos escritores mallorquines que más activamente contribuyeron a la reivindicación de Cervantes, sobre todo desde la prensa catalana. Me refiero al maurista Miquel dels Sants Oliver y al socialista Gabriel Alomar. Ambos poseían, según Joan Estelrich, «un sentit hispànic dels problemes de llur temps» y defendían, desde polos opuestos, las mismas ideas fundamentales: «Les idees concretes de l'autarquia espiritual, de la reforma estatal i de la concòrdia hispànica; les idees generals de l'ordre i de la justícia, i de la civilització que n'és el resultat.»9

Ya en 1903, a raíz de la propuesta de conmemoración del Tercer Centenario, lanzada desde El Imparcial por Mariano de Cavia, Miquel dels Sants Oliver publicó un artículo en La Veu de Catalunya, «El Centenari del Quijote» (11 de desembre), ${ }^{10}$ en el que expone sin ambages la conveniencia de que Cataluña, principalmente a través del Ateneu y de la Acadèmia de Bones Lletres, se sume al evento:

Raons elementals de civilització i de política aconsellen a la nova Catalunya que prengui sa part en el centenari del Quijote. Si en determinades ocasions cal retreure els agravis i fer-los valer, la justícia i la gratitud han d'ésser més fortes quan se tracta d'aquelles personalitats altíssimes que suposen una desviació del temperament dominant i un esperit d'amplitud i de llarguesa capaç de produir, si prosperés qualque dia, la veritable i íntima comunió dels pobles ibèrics. ${ }^{11}$.

$\mathrm{Su}$ argumentación se basa en el alto concepto que le merece la personalidad y el genio de Cervantes — «un temperament antiinquisitorial, anticalde-

6. Alcover, Joan, Ibíd., p. 21.

7. Alcover, Joan, Ibíd., p. 23.

8. Como veremos más adelante, esa falta de prejuicios se convierte en verdadero deseo de identificación con el legado cervantino en la traducción del Quijote de Ildefonso Rullán, que se publicó también aquel año.

9. Estelrich, Joan, «Pròleg» a Miquel dels Sants Oliver, Obres completes, Barcelona, Selecta, 1948, pp. XIV-XV.

10. Recogido en Oliver, Miquel dels Sants, Obres completes, ob. cit., pp. 714-718.

11. Oliver, Miquel dels Sants, «El Centenari del Quijote», Ibíd., p. 718. 
ronià $[\ldots]$ una naturalesa essencialment humana i humanitarista»- $\mathrm{y}$ de su criatura, don Quijote, una figura diametralmente opuesta a la de don Juan Tenorio, de quien arranca el destestable «camorrisme» de la literatura española. ${ }^{12}$ Poco más de un año después, en otro artículo de título homónimo, aparecido también en la misma publicación, el ensayista mallorquín insiste en el aprecio de la postura cervantina contra la intolerancia, en su espíritu magnánimo, su ironía benevolente, y «la gran epopeia de l'equilibri, de l'equanimitat i del bon seny» que es el Quijote. ${ }^{13}$

Y es que, más que su obra, es la persona de Cervantes, — precisamente porque representa todo lo contrario de «allò que retreuen a Espanya sos detractors» 14 — la que engendra en el mallorquín ese sentimiento de gratitud y profunda admiración que se destila de todos los estudios que le dedica. Sus investigaciones abarcan desde el proceso sobre la muerte de don Gaspar de Ezpeleta, ${ }^{15}$ a una monografía sobre «Las mujeres del Quijote», ${ }^{16}$ pasando por la relación entre Cervantes y Cataluña. ${ }^{17}$

Diez años más tarde, Oliver volvió a conmemorar también la aparición de la Segunda Parte con discursos ${ }^{18}$ y nuevas aportaciones en la prensa, ${ }^{19}$ que giran principalmente en torno a la vida de Cervantes, cuya biografía estaba preparando.

Como era de esperar, la publicación de Vida y semblanza de Cervantes supone la más importante contribución de Oliver al cervantismo. ${ }^{20}$ La edición está ilustrada con reproducciones de autógrafos y varias fotografías: la casa de doña Catalina de Salazar y Palacios en Esquivias, la placa conmemorativa de la que ocupó Cervantes en Alcalá de Henares, las portadas de las primeras ediciones del Quijote, etc. El volumen se cierra con un epílogo titulado «Cervan-

12. OLIVER, Ibíd., pp. 715-716.

13. Oliver, Miquel dels Sants, «El Centenari del Quijote», La Veu de Catalunya (21 de gener de 1905), recogido asimismo en sus Obres completes, ob. cit., pp. 772-777. Y del día siguiente es este otro: OLIVER, Miquel dels Sants, «Nostre homenatge. El centenari del Quijote», Ilustració Catalana. Tercer Centenari del Quijote, any III, nº 86, Barcelona, 22 de gener de 1905.

14. Oliver, Miquel dels Sants, Obres completes, ob. cit., p. 776.

15. Oliver, Miguel S., «Cervantes en Valladolid. Un proceso de 'capa y espada'», La Ilustración Artística, Barcelona 8 de mayo de 1905, nº 1219, pp. 299-300.

16. Oliver, Miguel S., «Las mujeres del Quijote», La Ilustración Artística, 1 de enero de 1905, $\mathrm{n}^{\circ}$ 1201, pp. 3-4.

17. Oliver, Miguel S., «Alrededor de un centenario: Cervantes y Cataluña», La Vanguardia, 24 de abril de 1905.

18. Por ejemplo, «De Cervantes», discurs llegit al Centre Autonomista de Dependents del Comerç i de la Industria, el dia 2 de juliol de 1916. Recogido en Oliver, Miquel dels Sants, Obres completes, ob. cit., pp. 1006-1016.

19. OLIVER, Miguel S., «Alrededor de un centenario: indagaciones cervantinas», La Vanguardia, 1 y 8 de mayo, 1915. «En torno al centenario: Cervantes en Sevilla, La Vanguardia, 7 de agosto, 1915. «Conversaciones del centenario: tres épocas de Cervantes» La Vanguardia, 2, 9, 16, 23 y 30 de octubre, 1915; también publicado en Palma: «Del centenario: tres épocas de Cervantes», La Almudaina, 13 y 19 de octubre, 1915. «De Barcelona: crónicas fugaces», La Ilustración Artística, XXXIV, n 1749 , 1915. «La estela del Quijote», ABC, 5 de mayo, 1916.

20. Oliver, Miguel S., Vida y semblanza de Cervantes, Montaner y Simón, Editores, Barcelona, 1916. 
tes y Cataluña», en el que el mallorquín insiste en su empeño de presentarlo como piedra angular entre las diversas culturas hispánicas:

Así era, y así le vemos y reverenciamos a Cervantes: el más alto valor que haya producido hasta ahora el vasto conjunto de la civilización ibérica, y uno de aquellos a quienes debe Cataluña más entrañable comprensión por obra de generosidad y simpatía, que no en vano es el amor llave o camino del puro conocimiento. ${ }^{21}$

Esta misma biografía, convenientemente adaptada, constituye el pórtico de la lujosa edición del Quijote preparada por Francisco Rodríguez Marín y con comentarios de Juan Givanel, publicada por Montaner y Simón en 1930.

Por su parte, el tributo más importante de Gabriel Alomar es, sin lugar a dudas, la serie de artículos «Sobre el Quijote. Notes marginals», que aparecieron a lo largo de 1905 en el periódico El Poble Català. ${ }^{22}$ Unas notas de las que su autor debía de sentirse satisfecho puesto que las tradujo al castellano dos años más tarde para publicarlas en la revista de Gregorio Martínez Sierra y, aún una década después, volvió a incluirlas en su recopilación de ensayos Verba, aunque cambiando ligeramente el título: «Notas al margen de mi Quijote». ${ }^{23}$

Como se adivina desde el encabezamiento, Alomar, adoptando una perspectiva diametralmente opuesta a la de Oliver, pone el énfasis en el personaje más que en su creador. A partir de una lectura muy personal, ${ }^{24}$ que se pretende en todo punto contraria a la «interpretación corriente que se ha hecho del Quijote», ${ }^{25}$ dirige todos los elogios al protagonista de la obra, cuyo espíritu considera que está muy por encima del de Cervantes. ${ }^{26}$ Para Alomar, don Qui-

21. Oliver, Miguel S., Ibíd., p. 367.

22. Se encuentran en los números 19, 20, 27, 30, 32, 38, 40, 47 y 51. Tomo la referencia de RIERA, Carme, El Quijote desde el nacionalismo catalán, en torno al Tercer Centenario, Barcelona, Destino, 2005, pp. 236-237.

23. Alomar, Gabriel, Verba, Madrid, Biblioteca Nueva, s.a. La edición va precedida por un prólogo de Azorín, fechado en agosto de 1917, pp. 15-75. La versión de ese mismo texto publicado en $R e$ nacimiento solo recoge la primera parte de la serie (véase Alomar, Gabriel, «Sobre el 'Quijote'. (Notas marginales)», Renacimiento marzo 1907, número 1, pp. 168-203). Alomar tenía intención de publicarla íntegra ya que anuncia: «Concluirá en el número próximo», pero ese ofrecimiento no se cumplió, probablemente, para dar paso al más influyente e innovador de sus ensayos, me refiero a «Futurismo», cuya primera parte sí apareció traducida al castellano en Renacimiento, septiembre 1907, ${ }^{\circ}$ II, pp. 257-276.

24. «No sé de otro libro que ofrezca al lector tentaciones más fuertes para entregarse a aquella continuada lírica mental del pensamiento del autor, a aquel vagoroso y dulcísimo poetizar infinitamente el motivo sugerido, buscando el fondo inexistente de los ensueños entresentidos; a aquella deliciosa sensación de extraviarse por lejanías discretamente abiertas sobre las cosas por el poeta, divagación inefable en que, para quien sabe sentir, se resuelve y consiste la crítica.» (Alomar, Gabriel, Verba, ob. cit., p. 54).

25. Alomar, Gabriel, Ibíd. p. 61.

26. Alomar considera que «Tal vez Cervantes no sentía directamente la alteza espiritual de su héroe $[\ldots]$ era, después de todo, un español de su época [...] y sobre él pesaba la mole de un mundo tiránico y de una religión nacionalista, funeraria, enemiga de la vida y del placer», en tanto que don Quijote es el hijo que «se rebela contra el espíritu del padre» (AlOMAR, Gabriel, Ibíd. p. 40). 
jote personifica, entre otras cosas, «el triunfo de la Voluntad sobre la Realidad, del Yo sobre el No-Yo». ${ }^{27}$ Ya antes había afirmado que es la «encarnación del futuro aristocratismo humanitario, neocristiano, ansioso de la dignificación de los humildes y el imperio de la bondad y de la justicia». ${ }^{28}$ En las páginas finales de su disertación, se muestra también contrario a emparejar a Sancho con el «sentido común», su excelencia radica en que supone la «rehabilitación del ideal de la villanía», es decir, del pueblo. Un ideal que Alomar cifra en ser fiel al cometido de su señor, es decir, de quien dirige una «misión sobrehumana y trascendental que ha de renovar el mundo», aunque, por descontado, el hombre del pueblo no sea consciente de ello: «Sigue, porque seguir es su deber, y no puede dejar de cumplirlo.» 29

En definitiva, para el político socialista, el Quijote es «la síntesis poderosa de todo el idealismo medioeval», ${ }^{30}$ cuyo último refugio es el quijotismo, individualista y puro, que, en su opinión, fue arrinconado por el Renacimiento, escarnecido por el «tenorismo» y definitivamente degollado en Villalar por Carlos V. ${ }^{31}$ Acorde con sus convicciones, la paráfrasis de Alomar se dirige, pues, a la defensa de la voluntad utópica que gobierna las actuaciones de don Quijote. Lejos del primer grito unamuniano «iMuera don Quijote!», Alomar coincide de pleno con la percepción poética del Unamuno de la Vida de don Quijote y Sancho — que, como es sabido, vio la luz en 1905-, en tanto que defiende sin ambages una lectura simbólica completamente subjetiva. Comparte la fe unamuniana en que el mundo debe ser creación de la voluntad, en este caso de la voluntad de don Quijote; sostiene la necesidad de la locura idealista frente a la chata y rastrera realidad circundante, y, por si fuera poco, trasluce la misma desconfianza unamuniana sobre la capacidad del propio Cervantes de entender la verdadera dimensión simbólica de sus personajes. ${ }^{32}$

Otro trabajo digno de ser mencionado es el del jesuita Juan Mir Noguera sobre El centenario quijotesco. ${ }^{33}$ Se trata de un diálogo, more platónica, entre

27. Alomar, Gabriel, Ibíd., p. 47. (Las mayúsculas son del autor).

28. Alomar, Gabriel, Ibíd., pp. 36-37.

29. Alomar, Gabriel, Ibíd., p. 64.

30. Alomar, Gabriel, Ibíd., p. 75.

31. Véase, lo expuesto por propio Alomar en su artículo, palmariamente censurado — está lleno de líneas tachadas-, «Els dos esperits», Catalonia, 15-30 setembre, 1898, p. 215, parte del cual traduce en la nota 1 (pp. 18-19) del ensayo que venimos comentando.

32. Sobre las coincidencias del pensamiento de Alomar con el de don Miguel, véase UnAmUNO, Miguel de, «Sobre la lectura e interpretación del Quijote», en La España Moderna, abril 1905, n 196, pp. 5-22. También en Unamuno, Miguel de, Obras completas, edición de Manuel García Blanco, Madrid: Escelicer, vol. III, pp. 842-860 (cito por esta edición). En ese artículo, Unamuno manifiesta abiertamente sus prevenciones contra Cervantes: «Cervantes es un caso típico de un escritor enormemente inferior a su obra» [...] «Don Quijote es inmensamente superior a Cervantes» (p. 852). Cervantes no entendió «a derechas» a don Quijote (p. 853). Y, sobre todo, su aversión a las interpretaciones de cervantófilos y cervantistas, ataca, en concreto, los trabajos de Pellicer y Clemencín, en tanto que reclama una buena edición del Quijote: «Todo consiste en separar a Cervantes del Quijote y hacer que a la plaga de cervantófilos o cervantistas, sustituya la legión sagrada de los quijotistas. Nos falta quijotismo tanto cuanto nos sobra cervantismo» (pp. 851-852).

33. Mir Noguera, Juan, El centenario quijotesco, Madrid, Sáenz de Jubera, hermanos, 1905. 
tres personajes, Neanisco, Gamentes y Geroncio, que exponen sus respectivas opiniones sobre la cuestión. En realidad es un alegato contra los políticos que hacen demagogia promoviendo festejos con la excusa de celebrar el Centenario. Arremete también contra las academias, centros literarios, ayuntamientos, periódicos y particulares, que homenajean al Quijote más que a la Summa de santo Tomás, los Nombres de Cristo de fray Luis o el centenario de la muerte de Isabel la Católica, entre otros, que también le parecen más relevantes. Pero, sobre todo, es una diatriba contra la caterva de «modernos» que infestan de galicismos el castellano. Considera que el Quijote es fundamentalmente una parodia, mediante la cual Cervantes quiso extirpar del país a los quijotes, quijotillos, quijotines, quijotuelos, etc. y se duele de que no lo consiguiera, puesto que asoman por todas partes. El padre Mir concluye su invectiva con estas palabras: «no intentamos quebrar aquí contra nadie el enojo, sino solamente contra la galiparla, culpable de tantos desafueros. A Dios». ${ }^{34}$

Cuarenta años después, los mallorquines tampoco se olvidaron de aportar su granito de arena para rememorar el cuarto centenario del nacimiento de Cervantes en 1947. En esa oportunidad, el filólogo, humanista, traductor y poeta Llorenç Riber i Campins participó junto a otros académicos en varios actos de homenaje, tales como la Reunión extraordinaria del Instituto de España ${ }^{35}$ y el número conmemorativo que le dedicó el Boletín de la Real Academia Española. En este último, la contribución de Riber se centra en «identificar la personalidad histórica y civil de ese 'Roque Guinart' que dice Cervantes, y que no es más que el Perot Roca Guinarda». ${ }^{36}$ Figura sobre la que aporta numerosos datos, además de reproducir algunas de las letras de desafío del temible bandolero.

También a propósito de la misma conmemoración, otros dos mallorquines, el librero Lluís Ripoll y el bibliófilo cervantista Miquel Bordoy Cerdá37 publicaron un cuadernillo en papel tela, en el que el primero reseña los pasajes del Quijote en los que se mencionan libros; el segundo, apoyándose en las investi-

34. Mir Noguera, Juan, Ibíd., p. 245.

35. RIBER, Lorenzo et al., Reunión extraordinaria del Instituto de España celebrada [...] 18 de octubre de 1947 [...] para conmemorar el IV Centenario del nacimiento de Miguel de Cervantes Saavedra, Madrid: Instituto de España, 1947.

36. RIBER, Lorenzo, «Al margen de un capítulo de Don Quijote (El LX de la Segunda Parte)», Boletín de la Real Academia Española, número especial para conmemorar el Cuarto Centenario del nacimiento de Cervantes, tomo xxvii, octubre 1947 - abril 1948, (1948, pp. 79-90) p. 81.

37. Miguel Bordoy Cerdá nació en Felanitx en 1912 y falleció en Palma en 1980, fue socio de honor de la Sociedad Cervantina de Madrid, y reunió una importante colección apodada «Biblioteca y museo cervantinos» en su finca de Miner (Llucmajor), cuyo contenido en 1971, según el cómputo del propio Bordoy, era el siguiente: «452 ediciones del Quijote en 42 idiomas diferentes, 124 biografías de Cervantes, 624 obras de antología, crítica y escritas por Cervantes, 16.000 artículos periodísticos, música cervántica, calendarios, felicitaciones, bustos, cajas de cerillas, tabaco, vinos, pendientes, dijes, gemelos, broches, abanicos, naipes, repujados, ceniceros, pañuelos, almohadones, jarrones, sellos, planos topográficos, facsímiles, vasos, juegos de café y de cerveza, chocolates, azúcar, aceiteras, botellas, platos, una vajilla de Talavera, una reproducción de la copa de cristal de Venecia con incrustaciones de plata, etc. etc.» (Bordoy Cerdé, Miguel, Mallorca, Lepanto y Cervantes, Palma de Mallorca, Cort, 1971, p. 115). 
gaciones de Francisco Fernández Cuevas, sostiene que el correlato real de don Quijote fue Alonso de Quijada, tío de doña Catalina de Salazar, y que Cervantes, gallardamente, pospuso la publicación de la primera edición del Ingenioso hidalgo don Quijote de la Mancha hasta tener constancia de su fallecimiento. ${ }^{38}$

Ya en los 50, Bordoy atrajo la atención sobre el mencionado Ildefonso Rullán y las razones que le habían impulsado a trasladar el Quijote al catalán de Mallorca. ${ }^{39}$ La versión de Rullán, como veremos más adelante, había aparecido a manera de folletín en el semanario El Felanigense, y estaba especialmente dirigida a los payeses, menestrales y estudiantes de aquella localidad mallorquina, Felanitx, de la que Bordoy era oriundo.

En 1958 el propio Bordoy Cerdá volvió sobre Cervantes, esta vez desde la perspectiva de los poetas. ${ }^{40}$ Sin embargo, su principal aportación llegaría en 1971 con el libro Mallorca, Lepanto y Cervantes. ${ }^{41}$ En este interesante ensayo, Bordoy recoge cualquier referencia que permita establecer un vínculo, por tenue que sea, entre Cervantes y Mallorca o los mallorquines, a partir de diversos documentos históricos y de los datos ofrecidos en las numerosas biografías de Cervantes (cita, concretamente, las de Fernández de Navarrete, Clemencín, Pérez Pastor, Haedo, Rodríguez Marín, Mariano Tomás, Jaime de Armiñán, Miquel del Sants Oliver, Juan Luis Estelrich y Luis Astrana Marín). En síntesis, las «jornadas» en que está dividido el libro hacen referencia a los siguientes hechos: la presencia de piratas turcos en Mallorca y las fortificaciones levantadas para prevenir sus ataques; la llegada de don Juan de Austria al puerto de Andratx «para proveerse de vituallas y municiones», ${ }^{42}$ y su amistad con el franciscano Miguel Serviá, que se convirtió en consultor y confesor del príncipe, amén de cronista oficial de la batalla de Lepanto; ${ }^{43}$ la presencia documentada de otros mallorquines en la «mayor ocasión que jamás vieron los siglos»; el regalo de don Juan de Austria a fray Miguel de un crucifijo de marfil que aquel había recibido de manos del papa Pío V, y los avatares sufridos por la preciosa imagen, conservada en el convento de Jesús hasta la desamortización de Mendizábal de 1835, y hoy en paradero incierto; ${ }^{44}$ el cautiverio de Cervantes en Argel y la negociación de su puesta en libertad por parte de los frailes mercedarios, entre los que se encontraba otro mallorquín, fray Jerónimo Antich, a consecuencia de la cual, pudieron liberar a Rodrigo. Describe también la fallida expedición organizada por este para ir a rescatar a su hermano,

38. RIPOLL, Luis, «Cervantes y los libros» y BordoY, Miguel, «¿Existió don Quijote?», ambos en Cervantes: 1547-1947, Palma de Mallorca, Libros Ereso, 1948, pp. 9-14 y 17-22, respectivamente.

39. Bordoy CERdÁ, Miguel, «Ildefonso Rullán, traductor del Quijote al mallorquín», Anales cervantinos, II, 1952, pp. 427-430. Y el opúsculo Bordoy CERDÁ, Miguel, La traducción mallorquina del Quijote, Colección Panorama Balear. Monografías de arte, vida, literatura y paisaje, Palma de Mallorca, Imp. Mossèn Alcover, $\mathrm{n}^{\circ}$ 55, 1956.

40. Bordoy Cerdá, Miguel, Los poetas y Cervantes, Madrid, Imp. Viuda de Galo Sáez, 1958.

41. Bordoy Cerdá, Miguel, Mallorca, Lepanto y Cervantes, Palma de Mallorca, Cort, 1971.

42. Bordoy CERdÁ, Miguel, Ibíd., p. 33.

43. Bordoy Cerdá, Miguel, Ibíd., pp. 35-40.

44. Bordoy Cerdá, Miguel, Ibíd., pp. 74-76. 
sirviéndose de una fragata al mando del capitán Viana con marineros mallorquines, ibicencos y valencianos, que salió de Mallorca el 20 de septiembre de $1577 .{ }^{45}$ Por último, en la «Jornada $15 »$ se encuentra una interesante memoria «Contribución de Mallorca al cervantismo», ${ }^{46}$ en la que están relacionadas además de las aportaciones críticas, los diferentes homenajes, exposiciones bibliográficas, conferencias y manifestaciones artísticas más o menos lúdicas con que los mallorquines han honrado la memoria de Cervantes.

Igualmente es digno de ser recordado el interés que la poeta Celia Viñas ${ }^{47}$ puso en trasmitir su entusiasmo por la figura del autor del Quijote a sus alumnos del Instituto de Almería, donde desarrollaba una admirable labor educativa y cultural como catedrática de Literatura Española. En 1949 sus colegas le dedicaron un homenaje, con ocasión del cual, publicaron un trabajo titulado «Estampas de la vida de Cervantes» que Viñas había escrito dos años antes. ${ }^{48}$ Se trataba de unos apuntes, especialmente destinados «Para los quince años de todos los españoles», en los que la autora entresaca datos de los rastros autobiográficos que Cervantes fue desperdigando en algunas de sus obras. Agotada la edición, años después, y promovida también por los profesores del instituto almeriense, volvió a publicarse una parte de aquellas Estampas, concretamente la correspondiente a las apodadas «lecciones», que son las que contienen sus estudios críticos sobre algunas obras cervantinas. ${ }^{49}$

Precisamente por su rareza, tampoco quiero dejar de referirme a la monografía de Guillermo Morey Mora, en la que, a lo largo de más de trescientas páginas, mantiene la peregrina hipótesis de que el auténtico autor de la primera parte del Quijote no es Cervantes sino El Greco, convertido a la vez en «personaje involuntario de su propio libro». ${ }^{50}$ Anteriormente, su confesada fascinación por el Quijote había llevado a Morey a investigar sobre los «Puntos de relación entre la Historia de Don Quijote de la Mancha y el Llibre de

45. Bordoy Cerdá, Miguel, Ibíd., pp. 96-103.

46. Bordoy CERdÁ, Miguel, Ibíd., pp. 108-115.

47. Celia Viñas Olivella, aunque nacida en Lérida en 1915, vivió desde niña en Palma, razón por la cual es considerada mallorquina. Discípula de Gabriel Alomar, está muy lejos de compartir sus opiniones sobre Cervantes.

48. Viñas Olivella, Celia, Estampas de la vida de Cervantes, Almería, Dirección General de Archivos y Bibliotecas. Ayuntamiento de Almería. Biblioteca 'Francisco Villaespesa', 1949.

49. Viñas Olivella, Celia, Lecciones cervantinas, Almería, Librería Editorial Cajal S. L., 1976. Se trata de tres lecciones que aparecen bajo los epígrafes: «Las armas y las Letras (Italia, el dichoso día, la historia del cautivo, 'La libertad y La Galatea. Primera y fácil lección de literatura castellana sobre la obra de Cervantes: La Galatea'». «La novela ejemplar (la novia de Cervantes, 'El gran teatro del mundo. Segunda y fácil lección sobre literatura cervantina', el recaudador de contribuciones, vencida la invencible)». «El ingenioso hidalgo (hambre y sed de justicia, Don Quijote de la Mancha, ejemplo y ejemplares, El viaje al Parnaso [sic], y Los trabajos de Persiles y los trabajos de Miguel de Cervantes. Última lección de vida y literatura)».

50. Morey Mora, Guillem, El Greco, personaje y autor secreto del Quijote: estudio del "sustrato de creación” de la historia del Ingenioso Hidalgo, Palma de Mallorca, Edición del autor, 1969. Hace pocos años, Morey Mora en colaboración con Guasp Rovira ha vuelto sobre tan exotérico tema en otro libro. (Véase Morey Mora, Guillem y Guasp Rovira, Mercedes, Yerros sobre cenizas de gloria, Palma de Mallorca, Calima Ediciones, 2002). 
Orde de Cavalleria de Ramón Llull» ${ }^{51}$ para participar en el Congreso Internacional de Lulismo celebrado en Formentor en 1960.

Capítulo aparte merece otro mallorquín, Josep $\mathrm{M}^{\mathrm{a}}$ Casasayas Truyols, en mi opinión, uno de los más tenaces impulsores del fervor cervantista durante el último tercio del siglo pasado. Este investigador, que nunca presumió de serlo, reunió en su persona tres facetas relevantes del cervantismo: fue bibliófilo, estudioso de Cervantes y excelente traductor del Quijote. ${ }^{52}$

La biblioteca cervantina de Casasayas, actualmente propiedad de la Universitat de les Illes Balears, ${ }^{53}$ está compuesta por más de veinticuatro mil volúmenes, entre los que destacan las setecientas treinta y una ediciones del Quijote, y la colección de traducciones de la obra a veinticuatro lenguas distintas. Aparte de la cantidad de monografías sobre la persona y la obra de Cervantes, resulta asombroso el acopio y clasificación de los innumerables estudios cervantinos recogidos en revistas, recortes de artículos de prensa y material reprografiado, que forman parte de su recopilación. No en vano, Casasayas, como antes hicieran Isidre Bonsoms, José María Asensio o Juan Sedó, dedicó buena parte de su vida a reunir y ordenar todo cuanto encontraba relacionado con Cervantes.

Fruto de sus incansables pesquisas por bibliotecas, catálogos, colecciones, exposiciones y librerías de lance del mundo entero, es el Ensayo de una guía de bibliografía cervantina. ${ }^{54}$ Casasayas justifica en el prólogo la utilización de la palabra 'ensayo' porque «no se trata más que de un intento», dado que su propósito es llegar a abarcar la bibliografía cervantina en su totalidad. Este adelanto, quiere ser, además, una «guía» de bolsillo, una especie de vademécum para evitar que cervantistas incautos ${ }^{55}$ sean presa fácil de libreros desaprensivos. En realidad, lo que el propio autor considera como «simple repertorio» contiene la descripción de más de seiscientas ediciones del Quijote, sazonadas con todo tipo de comentarios críticos. El plan proyectado por Casasayas, que malogradamente no pudo llegar a culminar, estaba ideado para repartir la bibliografía en no menos de IX tomos, a saber:

I. Introducción general; II. Bibliografía de bibliografías; III. Obras completas y agrupadas; IV. La Galatea; V. Don Quijote. Eds. castellanas 16051915; VI. Id. Id. 1915-2005; VII. Id. Traducciones; VIII, IX, etcétera. ${ }^{56}$

51. La ponencia fue publicada dos años después en la revista Estudios Lulianos, 1962, Núms. 1617, pp. 117-126.

52. Desgraciadamente, Casasayas falleció en septiembre de 2004, antes de ver cumplido su propósito de sacar a la luz su versión mallorquina del Quijote, en la que venía trabajando más de treinta años, coincidiendo con la conmemoración del cuarto centenario. Como veremos más adelante, sus herederos se ocuparon de hacer realidad ese deseo.

53. La Universitat de les Illes Balears adquirió todo el fondo en 1996 de manos del propio Casasayas.

54. CASASAYAs, José Ma $\mathbf{M}^{\mathrm{a}}$ Ensayo de una guía de bibliografía cervantina. Ediciones castellanas del Quijote hasta su tricentenario (1605-1915), Tomo V, Ciudad de Mallorca, a costa del autor, 1995.

55. Entiendo que, a juicio de Casasayas, son cervantistas todos aquellos que se interesan por Cervantes y su obra.

56. Casasayas, José $\mathrm{M}^{\mathrm{a}}$, ob. cit., p. viii. 
Como estudioso, intervino en coloquios y congresos. Sus ponencias se plasmaron después en ensayos interesantes y bien documentados, como «La edición definitiva de las obras de Cervantes», 57 «Sancho Panza a tres horas del alba (comentario a $D Q$ I, 20, aventura de los batanes)», ${ }^{58}$ y «Don Quijote en el siglo XX. Breve repaso a las más recientes ediciones eruditas». ${ }^{59}$ Casasayas colaboró también en la edición del Quijote promovida por el Instituto Cervantes con el capítulo «Lugares y tiempos en el Quijote». ${ }^{60}$ Volcó, además, un enorme aparato crítico en la introducción y notas de su propia traducción del Quijote, la única versión al catalán que puede considerarse con todo rigor absolutamente íntegra.

Cabe añadir que este entusiasta propagador del cervantismo fue fundador, en 1988, de la Asociación de Cervantistas, desde cuyo seno impulsó una cantidad de actividades verdaderamente notable. ${ }^{61}$

También con ocasión del cuarto centenario, el escritor y periodista Miquel Ferrà Martorell publicó un tomito titulado Cervantes, el Quixot i Mallorca, ${ }^{62}$ donde recoge una miscelánea de diversos episodios cervantinos que guardan algún tipo de conexión con Mallorca. Esta nueva recopilación es a todas luces deudora del ya comentado estudio Mallorca, Lepanto y Cervantes de Bordoy Cerdá, pese a que Ferrà no lo cita como fuente fundamental. Lo más interesante del opúsculo quizás sea el último apartado: «Aportació bibliogràfica cervantina relacionada amb Mallorca», ${ }^{63}$ obra no de Ferrà sino del editor Miquel S. Font. Este, además de apoyarse en el catálogo de Joan Givanel, pone al día las mencionadas referencias de la «Jornada 15: Contribución de Mallorca al cervantismo», acopiadas años antes por Bordoy. ${ }^{64}$ Sin embargo, la lista de Font (artículos, discursos, conferencias, actas, ediciones, traducciones, certá-

57. Casasayas, José $\mathrm{M}^{\mathrm{a}}$, «La edición definitiva de las obras de Cervantes», Cervantes: Bulletin of the Cervantes Society of America, 6.2, 1986, pp. 141-190.

58. CASASAYAS, José $\mathrm{M}^{\mathrm{a}}$, «Sancho Panza a tres horas del alba (comentario a $D Q \mathrm{I}, 20$, aventura de los batanes)», ACer, 25-26, 1987-1988, pp.121-145.

59. CASASAYAS, José $\mathrm{M}^{\mathrm{a}}$, «Don Quijote en el siglo XX. Breve repaso a las más recientes ediciones eruditas», Anthropos, Suplemento, 17, dedicado a Miguel de Cervantes en su obra. Antología, selección de estudios y documentación, 1989, pp. 289-296.

60. Casasayas, José Ma , «Lugares y tiempos en el Quijote», en Cervantes, Miguel de, Don Quijote de la Mancha, Edición del Instituto Cervantes, dirigida por Francisco Rico. Volumen complementario, Barcelona, Instituto Cervantes-Crítica, 1998, pp. 911-933.

61. La Asociación patrocinada por Casasayas cuenta entre sus miembros con las figuras más notables del cervantismo internacional y promueve, desde 1991, la celebración de congresos internacionales cada tres años (Almagro; 1994, Nápoles; 1997, Menorca; 2000, Lepanto; 2003, Lisboa; y 2006 Alcalá de Henares) y de Coloquios de ámbito nacional (más de una docena), cuyas actas van saliendo a la luz gracias al esfuerzo y tesón de quien fue secretario de Casasayas, el profesor Antonio Bernat Vistarini de la Universitat de les Illes Balears. Desde el fallecimiento de su fundador, la Asociación ha continuado con sus actividades y publicaciones cervantinas (véase la Web vinculada al Portal del Hispanismo: http://www.hispanismo.es/Asociaciones.)

62. Ferrà Martorell, Miquel, Cervantes, el Quixot i Mallorca, Palma, Miquel Font, editor, 2005.

63. Ferrà Martorell, Miquel, ob. cit , pp. 59-66.

64. Bordoy Cerdá, Miguel, Mallorca, Lepanto y Cervantes, ob. cit., pp. 108-115. 
menes, colecciones de bibliófilos, etc.), aunque puede resultar útil, recoge menciones demasiado tangenciales. Por ejemplo, a veces solo las apunta por el hecho de que el trabajo apareciera en una revista como Papeles de Son Armadans editada en Mallorca; o porque fuera publicado en algún lugar de las Baleares; o bien porque el ilustrador, el grabador o el librero fueran mallorquines. Font llega incluso a registrar conferencias y ponencias sólo porque fueran pronunciadas en algún lugar de las islas. Es obvio que muchas de esas fichas no deben ser clasificadas dentro del «cervantismo mallorquín». En sentido contrario, sorprende aún más alguna que otra ausencia.

Concretamente, ha llamado mi atención que, en tan abigarrado repertorio, no aparezcan referencias a las investigaciones que la escritora mallorquina Carme Riera ha dedicado a Cervantes, ${ }^{65}$ entre estas, varias de reconocida importancia. En junio de 2002, centró su discurso de entrada en la Real Academia de Buenas Letras de Barcelona en un estudio exhaustivo sobre las encrespadas disputas que tuvieron lugar en la prensa barcelonesa entre partidarios y detractores de la celebración del Tercer Centenario de la aparición del Quijote. ${ }^{66}$ En aquella disertación Riera recorrió las páginas de los periódicos y revistas siguientes: La Academia Calasancia, La campana de Gracia, Cataluña, El Correo Catalán, Diario de Barcelona, El Diluvio, La Esquella de la Torratxa, Hojas Selectas, La Hormiga de Oro. Ilustración Católica, Ilustració Catalana, La Ilustración Artística, Joventut, El Liberal, Las Noticias, El Noticiero Universal, El Poble Català, La Publicidad, La Renaixensa, Revista Musical Catalana, La Tralla, La Tribuna, La Vanguardia, y La Veu de Catalunya, para establecer los ejes de una polémica tras la que, en realidad, se ocultaba una cuestión más palpitante aún: el sempiterno debate Cataluña-España, a día de hoy todavía sin resolver. No hace falta añadir que solo la mención de tal recorrido sugiere la importancia e interés de una indagación de primerísima mano. Fruto también de esta investigación son los artículos «Casticismo y regionalismo en torno al Quijote» ${ }^{67}$ y «El Quijote desde el nacionalismo catalán», ${ }^{68}$ que, a su vez, anticipan la publicación del volumen El Quijote desde el nacionalismo catalán, en torno al Tercer Centenario, ${ }^{69}$ que vio la luz con ocasión del Cuarto.

Ese mismo año, Riera fue comisaria de la exposición «El Quixot i Barcelona» organizada por el Museu d'Història de la Ciutat, y editora del hermoso

65. Riera es catedrática de Literatura Española de la Universidad Autónoma de Barcelona.

66. RIERA, Carme, La recepció del Tercer Centenari del 'Quixot' a la premsa de Barcelona (1905), Barcelona, Reial Acadèmia de Bones Lletres, 2002, pp. 5-96.

67. RIERA, Carme, «Casticismo y regionalismo en torno al Quijote», Insula, número dedicado a La recepción del Quijote en su IV Centenario, abril-mayo 2005, nº 700-701, pp. 23-25.

68. RIERA, Carme, «El Quijote desde el nacionalismo catalán», Nueva Revista, julio-agosto, 2005, n 94 , pp. 48-67.

69. Riera, Carme, El Quijote desde el nacionalismo catalán, en torno al Tercer Centenario, ob. cit. Para un análisis detallado de esa obra, véase la reseña de PerCAS DE PONSETI, Helena, «Carme Riera: El Quijote desde el nacionalismo catalán, en torno al Tercer Centenario. Barcelona, Destino, 2005. 241 pp.», Cervantes, Bulletin of the Cervantes Society of America, Vol.XXVII, Spring 2006, no.1, pp. 231-235. 
catálogo, en el que se incluyen ensayos de cervantistas de primera fila. ${ }^{70}$ Organizó, junto con Guillermo Serés, el congreso internacional, promovido por la Universidad Autónoma de Barcelona y el Museu d'Història de la Ciutat, celebrado en abril de 2005, sobre «Cervantes, el Quixot i Barcelona». ${ }^{71}$ Tema del que se ha ocupado asimismo en diversas conferencias y artículos, entre los que destaco: «Cervantes, el Quijote y Barcelona (Hipótesis de una estancia barcelonesa de Cervantes en 1571)» ${ }^{72} \mathrm{y}$ «A vueltas con la tradición: de nuevo sobre Cervantes y Cataluña». ${ }^{73}$

En el primero, Riera trata de establecer la posibilidad de que Cervantes pasara por Barcelona no en 1610 sino en 1571 para embarcarse con las tropas de don Miguel de Montcada rumbo a Lepanto. Aduce para ello una serie de datos cuya interpretación resulta cuanto menos plausible. Serían, entonces, los recuerdos de aquellos días de juventud los utilizados por Cervantes para sazonar la estancia de don Quijote en tierras catalanas, al verse obligado a cambiar el itinerario de sus personajes sustituyendo Zaragoza por Barcelona después de aparecer el apócrifo de Avellaneda.

En el segundo ensayo, Riera vuelve a cuestionar la estancia barcelonesa de Cervantes, ahora, a partir de los datos que manuales y guías de Barcelona ofrecen a los viajeros desde mediados del siglo XIX. Así, la ubicación de la casa donde se hospedó Cervantes, en el actual Paseo de Colón, o el medallón con el hipotético retrato cervantino prendido de la fachada, cobran un sentido más promocional desde el punto de vista turístico que histórico. Riera deja al descubierto algunas de las inexactitudes e invenciones que adornan la tradición legendaria de la Ciudad Condal. Sin embargo, a juicio de la investigadora, el hecho de poder probar de manera fehaciente que Cervantes residiera o no unos días al amparo de sus murallas, no cambiaría en absoluto la importancia de los episodios catalanes del Quijote, puesto que fueron sus páginas, y no la constatación de las vivencias del autor, las que alimentaron la fama de Barcelona convirtiéndola, desde principios del XVII, en una auténtica ciudad literaria.

70. Tras una «Presentación» de Martí de RIQUER, el sumario incluye textos de los siguientes autores: RIERA, Carme, «Una exposición justificada»; Close, Anthony J., «La significación actual del Quijote en la literatura universal»; GARCíA CÁRCEL, Ricardo, «La España de don Quijote»; CANAVAGGIO, Jean, «Cervantes y Barcelona»; GARCíA EsPuche, Albert, «Barcelona 1610: 'Ciudad regalada'»; SERÉs, Guillermo, «El contexto históricosocial de los episodios catalanes del Quijote»; BuRGOS RINCón, Javier, «La imprenta de Barcelona en el tiempo del Quijote»; PEÑA, Manuel, «Leer en la Barcelona de Cervantes»; BlecuA, Alberto, «Las ediciones del Quijote en Cataluña», El Quijote y Barcelona, edición a cargo de Carme Riera, Barcelona, Lunwerg Editores, 2005. (El catálogo fue publicado simultáneamente en catalán, El Quixot $i$ Barcelona, por la misma editorial).

71. Las ponencias están recogidas en RIERA, Carme y SERÉs, Guillermo (dirs.), Cervantes, el «Quijote» y Barcelona, Barcelona Centro para la Edición de los Clásicos Españoles, 2007.

72. RIERA, Carme, «Cervantes, el Quijote y Barcelona (Hipótesis de una estancia barcelonesa de Cervantes en 1571)», Anales Cervantinos, vol. XXXVII, 2005, pp. 33-43.

73. RIERA, Carme, «A vueltas con la tradición: de nuevo sobre Cervantes y Cataluña», Boletín de la Real Academia Española, tomo LXXXV, cuadernos CCXCI-CCXII, enero-diciembre de 2005, pp.559-572. 
Riera ha contribuido, además, a la publicación de un pequeño volumen en el que se recogen las aventuras quijotescas en tierras catalanas ${ }^{74}$ y a la edición facsímil de la traducción al mallorquín de Ildefonso Rullán, a la que me referiré más adelante. ${ }^{75}$

En cuanto a las traducciones mallorquinas del Quijote, desearía advertir de entrada que, en mi opinión, obedecen a un doble propósito: $a$ ) honrar la figura de Cervantes, insistiendo en que el Quijote es la aportación española más importante a la literatura universal; y b) salvaguardar, sobre la falsilla de sus páginas, las peculiaridades lingüísticas y culturales de la variante dialectal mallorquina, considerada en trance de desaparecer. Temor que avala, en cualquier caso, la necesidad de un traslado, que, a priori, pudiera ser tildado de superfluo.

Según los datos de que disponemos hasta ahora, las primeras páginas del Quijote vertidas al catalán fueron obra del mallorquín Jaime Pujol, nacido en Artá en 1794 y fallecido en Palma en 1850. En palabras de José María Quadrado, Pujol fue «advocat de mérit en son temps i escriptor de facilísima vena», ${ }^{76}$ tanto que llegó a ser, durante una época, director del Diario Constitucional de Palma. ${ }^{77}$ A este jurista filólogo se le ocurrió traducir el capítulo XII de la primera parte del Quijote para ilustrar unas Observaciones sobre la ortografía mallorquina ${ }^{78}$ que quería sacar a la luz. En realidad, se trata de un breve compendio manuscrito sobre las peculiaridades dialectales de su lengua materna, comentadas al hilo de la versión que estaba llevando a cabo:

74. Cervantes, Miguel de, Don Quijote en Barcelona, «Prólogo» de Martí de RiQuer. «Epílogo» de Carme RiERA, Barcelona, Destino, 2005.

75. Véase la referencia en la nota 88.

76. Quadrado asegura que Pujol ocupó un lugar destacado en su propia formación y promoción. (QuAdrado, J. M., «Desagravi a les literatures regionals», Boletín de la Sociedad Arqueológica Luliana, t. 3, 1889, n. 102, pp. 73-75. Texto incluido en QUADRADO, Josep Maria, Assaigs literaris, edició a cura d'Antònia Tayadella, Barcelona, Publicacions de l'Abadia de Montserrat, 1996, pp. 233-238).

77. El periódico, fundado en 1820, pasó por diversas épocas y formatos. Pujol fue director durante la cuarta etapa ( 1 de octubre de 1839 a 31 de julio de 1845), en la que se encuentran las firmas de Quadrado, Antonio Montis, marqués de la Bastida, y Tomás Aguiló, entre otras.

78. Desconocemos a ciencia cierta la fecha de esta obra, por lo que a la traducción de Pujol le disputa la primacía la de Magí Pers i Ramona del capítulo XVIII de la I parte, que apareció en el anexo de la Gramática catalana-castellana, adornada ab exemples de bons autors, alguns diálogos familiars ab la correspondencia de les frases mes difísils de la llengua, y alguns trossos escullits en prosa y vers, ab la versió corresponent al costat (Barcelona: Imprenta de A. Berdaguer, 1847, pp. 229-233). Para un análisis extenso de la cuestión, véase BACARdí, Montserrat y EstANy, Imma, El Quixot en català, Barcelona, Publicacions de l'Abadia de Montserrat, 2006, pp. 152-154 y 148-152. En síntesis, estas investigadoras consideran que el traslado de Pujol es anterior, apoyándose en la datación establecida por Martínez i Taberner, que, a su vez, estima que las Obervaciones pujolescas salieron a la luz en 1846, es decir, un año antes de la publicación de la Gramática catalana-castellana de Pers i Ramona. (Véase MARTíneZ I TABERner, Catalina, «Jaume Pujol i la llengua catalana», Miscel-lània Jordi Carbonell IV. Estudis de llengua i literatura catalanes, XXV. Barcelona, Publicacions de l'Abadia de Montserrat, 1992, p. 94. Tomo esta referencia de BACARDí, M. y Estany, I., ob. cit., p. 148 , nota 99). 
Como las observaciones no se tienen á la mano recogidas y ordenadas, se traducirá á continuación un capítulo cualquiera del Quijote, en que se anotarán en letra bastardilla las observaciones que merecieren alguna atención. ${ }^{79}$

Nótese que, aunque don Jaime escriba sus comentarios en castellano, — dada su condición de lengua oficial y «uno de los más ricos idiomas que conoce el mundo civilizado» ${ }^{80}$ _, justifica la utilidad de sus Observaciones aduciendo que siempre habrá transacciones civiles y correspondencias epistolares en mallorquín «y para estos usos nunca será perdido un tratado de ortografía de nuestro particular dialecto». ${ }^{81}$ Aduce además que, como, a su juicio, en mallorquín no hay literatos en los que aprender, ha tenido que ponerse a traducir un capítulo del Quijote para aclarar con ejemplos sus Observaciones. Pujol, desde una visión bastante catastrofista, consecuente con la situación de diglosia a la que, por avatares políticos y sociales, había sido relegada la lengua vernácula, aboga por el uso y enseñanza del castellano por razones prácticas. Admite, pues, la preminencia de la lengua oficial y social versus la lengua familiar e íntima, pero no se resigna a su desaparición, muy al contrario, considera absolutamente obligado hacer todo lo necesario para salvaguardarla y su tratado es la mejor prueba de ello. En consecuencia, utiliza el prestigio y autoridad del Quijote como mediador idóneo de su consternado proyecto de conservación.

De este modo, Pujol se adelanta también en eso a otras traducciones mucho más ambiciosas, que utilizarán asimismo el Quijote como intermediario para probar la versatilidad y riqueza de la lengua catalana y de sus variantes dialectales. En ese sentido, cabe añadir que la preocupación de los traductores mallorquines no es debida sólo a que consideren que la pujanza del castellano puede acarrear la desaparición de la lengua vernácula, sino también al recelo de que las jugosas hablas locales acaben siendo absorbidas por el catalán estándar, en aras de una normativa uniformadora demasiado estrecha y categórica.

De un modo u otro, a partir del último cuarto del XIX, entre la exigua traducción de Pujol y la última traducción del Quijote, contamos con cinco versiones completas al catalán y no menos de veintisiete traducciones más, entre traslados parciales y adaptaciones. ${ }^{82}$ Las consideradas completas en el catalán del Principado son tres: $a$ ) la de Eduart Támaro, ${ }^{83}$ abogado e historiador, que solo consiguió ver publicada la primera parte en 1882, aunque la segunda se

79. El texto puede consultarse en su integridad reproducido por FERRER, Antoni-Lluc, «Don Quijote, I, XII: la traducció i les 'Observaciones' de Jaume Pujol», Randa, 1986, n 20, p. 213. No obstante, quien dió a conocer las Observaciones fue Massot i Muntaner, Josep, «La Societat d'Amics del País, Jaume Pujol i el català de Mallorca», In memoriam Carles Riba (1959-1969), Barcelona, 1973, pp. 261-275. Ensayo recogido después en MASsot i MunTANER, Josep, Els mallorquins i la llengua autòctona, Barcelona, 1985, pp. 117-136.

80. Pujol, J., ob. cit., p. 212.

81. Pujol, J., ob. cit., p. 213.

82. Véase el citado estudio de BACARDí, M. y Estany, I., El Quixot en català.

83. L'ingeniós hidalgo Don Quixot de la Mancha. Escrit per Miquel de Cervantes Saavedra y traduhit à la llengua catalana per D. Eduart Támaro, llicenciat en jurisprudencia. Primera part. Barcelona, Estampa de Cristófol Miró, 1882. 
conserva manuscrita en la Biblioteca de Catalunya; $b$ ) la de Antoni Bulbena i Tussell que salió a la luz en $1891 ;{ }^{84}$ y $c$ ) la de Joaquim Civera i Sormaní, ${ }^{85}$ publicada en 1969, que aunque comprende las dos partes y respeta la división de capítulos, se trata de otra versión en la que el traductor tiende a resumir, con bastante frecuencia, el contenido original. Las dos traducciones restantes son obra de sendos autores mallorquines, anteriormente aludidos: Ildefonso Rullán y Josep $\mathrm{M}^{\mathrm{a}}$ Casasayas.

Antes de centrarme en estas, apuntaré que existe otro breve traslado al mallorquín, publicado en 1905, en la revista Catalunya, dirigida por Josep Carner, que también se hace eco del tricentenario. Su autor fue Joan Rosselló de Son Forteza, de quien encontramos diversas colaboraciones en otros números de la citada revista. Su versión apareció bajo el rótulo «Escenes del Quixot». Estas «escenas» del Quijote son una traducción sintética, es decir, en la que se resume el contenido de los capítulos II y III de la primera parte ('La vetla de les armes') y del IX de la segunda ('La nit an el Tobosso'). ${ }^{86}$

Entre tanto, ese mismo año, como ya se ha dicho, el semanario isleño $E l$ Felanigense fue dando a conocer al público la primera versión completa del Quijote en la variante mallorquina. Su autor fue el clerigo Ildefonso Rullán, ${ }^{87}$ admirador de Cervantes — «Príncep de sas lletras castellanas»- y profundo conocedor de su obra. En Mallorca el éxito de la iniciativa fue tal que la traducción fue inmediatamente reunida en dos volúmenes, que recogen la primera y la segunda parte respectivamente. ${ }^{88}$ Además de contribuir a la celebración del Tercer Centenario, en la tarea de Rullán se trasparentan dos razones fundamentales: $a$ ) demostrar que el Quijote es traducible y $b$ ) que el mallorquín dialectal tiene recursos lingüísticos suficientes para recrear una obra de semejante envergadura.

84. L'enginyós cavaller don Quixot de la Manxa. Compost per Miquel de Cervantes Saavedra. Traslladat á nostra llengua materna, y en algunes partides lliurement exposat per Antoni Bulbena y Tusell. Barcelona, Tipografía de F. Altés, 1891. Hay que añadir que Bulbena se dedicó a corregir, recortar o rescribir su versión, dependiendo del público al que fuera destinada, casi cincuenta años de su vida. Su última revisión data de 1936. Con ocasión del cuarto centenario, se ha hecho una reimpresión: Cervantes, M. de, L'enginyós cavaller don Quixot de la Mancha, Barcelona, Edicions 62, 2005, añadiendo el «Pròleg» que escribiera Joan Givanel i Mas para la edición de 1930, y una ceñida «Presentació» a cargo de Montserrat Bacardí.

85. Cervantes, Miguel de, Don Quixot de la Manxa, traducció de Joaquim Civera i Sormaní, Barcelona, Tarraco, 1969.

86. Rosselló, Joan, «Escenes del Quixot» ('La vetla de les armes'; 'La nit an el Tobosso'), Catalunya, any III, 30 d'abril de1905, pp. 13-23.

87. Para una biografía del filólogo, véase Pons, Antoni, Mossèn Ildefons Rul·lan i el 'Quixot'. Esbos biogràfic. Palma de Mallorca, Gràfiques Miramar, 1969.

88. L'enginyós hidalgo Don Quixote de la Mancha. Compòst per Miquèl de Cervantes Saavédra y traduit ara en mallorquí sa primera vegada per n'Ildefonso Rullán, Prevere. Llicenciat en Filosofia y Lletras. Felanitx, Imprempta d'en Bartomeu Rèus, t. I, 1905; t. II, 1906. Con ocasión del cuarto centenario, esta traducción ha sido reeditada en facsímil aunque en un único volumen, precedida por un estudio de RIERA, Carme y CoTONER, Luisa, «Introducció: La traducció mallorquina d'Ildefons Rullan», L'enginyós hidalgo..., Palma de Mallorca, J.J. de Olañeta, Editor, «La Foradada», 2005, pp. xiii-Xxxii. 
Su interés en demostrar que el Quijote es perfectamente traducible arranca de la polémica — bastante peregrina por lo demás - que se había desatado en el último tercio del XIX entre José María Sbarbi y José María Asensio. Sbarbi estaba empeñado en establecer la intraducibilidad del Quijote ${ }^{89}$ Asensio, como era de esperar, defendía todo lo contrario. ${ }^{90}$ Rullán, aunque no tomó parte en la porfía, en las palabras preliminares a su traducción, argumenta que en el Quijote son más importantes las ideas que las palabras y que el libro «lluny de esser dificil de traduir, es per ventura de's mes facils». ${ }^{91}$ No pretende, por tanto, ser fiel a la letra sino producir en el lector un efecto estético equivalente, ya que, según Rullán, querer traducir su «lenguaje» — se refiere a traducir palabra por palabra - sería empeñarse en traducir el espíritu de Cervantes, lo que supondría, además de una gran temeridad y un grave defecto, el imposible de dar en otra lengua el «saborino» (saborcillo) literario que Cervantes le dio en la propia. No le preocupa que haya expresiones que no pueden ser dichas del mismo modo si las puede trasladar de manera similar; tampoco le importa suprimir palabras como «duelos y quebrantos», ya que ni siquiera - aduce- sabían en qué consistían los españoles de la época que no fueran de la Mancha; o dejar directamente en castellano aquellas palabras que, a su juicio, carecen de equivalencia en catalán. ${ }^{92}$ A partir de esos planteamientos, Rullán añade, cambia, adapta o suprime, todo cuanto le parece necesario para lograr retener la atención de sus principales destinatarios: aldeanos y campesinos, que después de un duro día de trabajo, se reunían alrededor de los que sabían leer para escuchar «rondalles» o, en este caso, las aventuras de don Quijote y Sancho, como si estos personajes formaran parte también de las narraciones tradicionales mallorquinas. ${ }^{93}$ La traducción de Rullán se propone ante todo la utilización de las variantes dialectales mallorquinas, y, como consecuencia, el alejamiento del estándar. Y eso es lo que da sentido al hecho de volver a trasladar al catalán un texto que ya contaba en aquella época con versiones tan meritorias como las citadas de Támaro y de Bulbena.

Por último, y sin restarle mérito a la innovadora labor de Ildefonso Rullán, la versión que marca un hito en las traducciones quijotescas, tanto por

89. SbARbI, José María, «El Quijote es intraducible», La Ilustración Española y Americana, 1 de mayo de $1872, \mathrm{n}^{\circ}$ XVII, pp. 262-263.

90. Asensio, José María, «¿Puede traducirse el 'Quijote’?», Cervantes y sus obras. Artículos. Barcelona, Seix Editor, 1902, pp. 175-187. Cito por esta recopilación porque mi búsqueda del texto publicado en prensa, probablemente, en 1873, ha resultado infructuosa. Unamuno, en el artículo antes citado «Sobre la lectura e interpretación del Quijote», también había tomado partido por esta opción: «es un libro perfectamente traducible, [...] su fuerza y poesía toda queda en él, viértase al idioma que se vierta» (UnAmuno, Miguel de, Obras completas, ob. cit., p. 851).

91. Rullán, Ildefonso, «Cuatre paraulas d'es traductor a n'es lectors», L'enginyós hidalgo Don Quixote de la Mancha, ob. cit. t. I, 1905, p. VI.

92. Rullán, Ildefonso, Ibíd., p. VII.

93. Para un análisis detallado de las estrategias traductoras de Rullán, véase COTONER, Luisa, «Una curiosa traducción del Quijote al mallorquín», Qué Quijote leen los europeos, en VEGA CERNUDA, Miguel A. (ed.), Madrid, Instituto de Traductores-Universidad Complutense, 2006, pp. 67-79. 
el espléndido resultado obtenido como por el aparato crítico que la acompaña, es la de Josep $\mathrm{M}^{\mathrm{a}}$ Casasayas, ${ }^{94}$

Tres son las pautas que Casasayas mantiene a lo largo de su traducción: $a$ ) el empeño de traducir absolutamente todo el texto, incluso los créditos de la portada de Juan de la Cuesta, quizás, por identificarse más aún con Cervantes, que, como es archisabido, leía hasta los papeles rotos de la calle; $b$ ) el interés por aclarar en nota aquello que pueda representar un escollo para los lectores; y c) la decidida voluntad de utilizar toda la diversidad de las hablas dialectales, especialmente las mallorquinas, para volcar en ellas el Quijote.

Casasayas titula su traducción L'Enginyós cavaller Don Quixot de la Manxa. Traducció integral amb explicacions i comentaris per Josep $M^{a}$ Casasayas Truyols, y la reparte en tres volúmenes, etiquetados con las siglas: $Q O$ (Volum preliminar. Introducció. Taula), ${ }^{95} Q 1$ (primera part) y $Q 2$ (segona part).

En el volumen preliminar, imprescindible para medir el alcance de lo que el traductor pretende hacer, se encuentran perfectamente descritos los objetivos que le llevaron a dedicarse durante más de treinta años a una tarea de tal magnitud. A diferencia de lo que ocurre con las traducciones de Támaro, Bulbena, y Rullán, en las que encontramos omisiones de todo tipo, Casasayas quiere ofrecer al lector una versión verdaderamente íntegra del libro de Cervantes. En efecto, lo traduce todo: los versos preliminares y los poemas intercalados, adaptando la métrica y la rima, la novela del «Curioso impertinente» (tantas veces escamoteada), todas las demás «historias», amén de la totalidad de los capítulos sin saltarse ni una línea, de manera que la suya es, sin duda, «la primera que conté el text castellà íntegre vertit a la nostra llengo». ${ }^{96} \mathrm{Ex}-$ presa también su intención de dejar testimonio perdurable de la diversidad de las modalidades dialectales habladas en las Baleares y Pitiusas, sin que prevalezcan los usos lingüísticos de una región sobre los de otra, ya que estima que esa diversidad está en peligro de desaparecer arrollada por las sucesivas campañas de «normalización», exclusivamente en pro del estándar barcelonés. Pretende, por descontado, rendir homenaje a Cervantes y, aunque admite no había ninguna necesidad de traducir el Quijote, arguye que tampoco Cervantes tenía necesidad de escribirlo, de manera que su dedicación obedece a dos

94. Cervantes SaAvedra, Miguel de, L'enginyós cavaller don Quixot de la Manxa, (3 vols.), traducció integral, amb explicacions i comentaris per Josep $\mathrm{M}^{\mathrm{a}}$ Casasayas Truyols, A costa del traductor, Ciutat de Mallorca, 2004. Esta edición, compuesta y maquetada por el propio Casasayas, fue publicada con el copyright de sus herederos en abril de 2005.

95. El contenido del llamado $Q 0$ abarca la presentación general de la obra, que comprende a su vez: la descripción de la estructura externa e interna de la traducción, el sistema de referencias utilizado, la bibliografía citada, la tabla de abreviaturas, y la justificación del ejemplar; 16 páginas en total, a las que sigue una extensa «Introducció» de 95 páginas, dividida en cinco apartados: 1. Cervantes: època, vida, obra; 2. Síntesi argumental; 3. Lloc i temps en el Quixot; 4. El Quixot en llengos catalanes. 5. La present traducció. A todo lo cual hay que añadir un apéndice, en el que se incluye una lista de palabras homógrafas diferenciadas por el acento, más un índice de nombres, que ocupa no menos de doscientas páginas.

96. Casasayas, J. Ma , «Introducció», en Cervantes SaAvedra, Miguel de, ob. cit., v. I, p. 63. 
principios: «d'admiració cap a Cervantes i d'amor cap a la nostra parla», a los que añade otra motivación, más contundente si cabe: lo mucho que ha disfrutado traduciendo y estudiando el texto cervantino. ${ }^{97}$

Casasayas utiliza como texto de partida las dos ediciones de Juan de la Cuesta, Madrid 1605 y 1615, además de la tenida por segunda del mismo editor y año, para el pasaje del robo del rucio de Sancho. También detalla las demás ediciones y estudios consultados (cita a Clemencín, Pellicer, Rodríguez Marín, Martín de Riquer, Salvador de Madariaga, Juan Bautista Avalle-Arce, Sevilla, Francisco Rico, entre otros muchos) para ilustrar con sus comentarios las innumerables notas a pie de página que incluye en su traducción. De hecho, hay apostillas de todo tipo y relativas a los ámbitos más diversos: geografía, mitología, estudios bíblicos, historia, lexicología, folklore, etc. etc.

Muy fiel en cuanto el contenido del original, la traducción de Casasayas adopta, como método traductor la domesticación, que, como es sabido, consiste en tratar de invisibilizar la tarea de traslado, apropiándose de tal manera del texto de partida que el resultado suene tan natural como si se tratara de una obra directamente escrita en la lengua receptora. Sigue en eso a Rullán, a quien cita agradeciéndole sus aportaciones, sobre todo, en lo referente a la traducción de locuciones, refranes y dichos populares. Casasayas, sin embargo, supera con creces a su antecesor en cuanto a procedimientos traductores y soluciones halladas. Casasayas recurre tanto a la lengua hablada como a la lengua escrita para poder abarcar las diferentes variantes diatópicas y diastráticas del catalán-balear, e incluso echa mano de otras variantes regionales haciendo que algunos personajes las utilicen. Así, por poner solo unos ejemplos, el general de las galeras habla en valenciano, el lacayo Tosilos, en aranés, y don Antonio Moreno, en el barcelonés estándar. ${ }^{98}$ De ese modo, Casasayas, amparado en las páginas protectoras de Cervantes, consigue salvar para la posteridad un testimonio impagable del vasto acervo de la lengua catalana. Todo ello sin enmendarle la plana al original y cuidando de no traicionar jamás el pensamiento cervantino ni, en la medida de lo posible, su riqueza expresiva.

En resumen, el interés y aprecio que Cervantes y su obra han despertado en los mallorquines ha sido una constante, plasmada en artículos, ensayos, estudios y traducciones, durante casi ciento sesenta años contando desde la breve traducción de Pujol hasta la última contribución erudita de Riera. Ciertamente, el acierto en la interpretación y el rigor filológico no son los mismos en todos los casos. Sin embargo, a mi juicio, todos han contribuido a perpetuar la peculiar fascinación que la lectura del Quijote ha venido suscitando a lo largo de cuatro siglos sea para trasladarlo a otra lengua, sea para indagar en las inagotables incógnitas que Cervantes y su obra continúan planteándonos.

97. Casasayas, J. Ma , Ibíd., pp. 64- 65.

98. Para un estudio más detallado de la traducción de Casasayas, véase CoTONER, Luisa, «El Quijote en mallorquín: la traducción integral de Josep Maria Casasayas», en RIERA, Carme y SERÉs, Guillermo (dirs.), Cervantes, el «Quijote» y Barcelona, dirs. Carme Riera y Guillermo Serés, Barcelona, Centro para la Edición de los Clásicos Españoles, 2007, pp. 75-89. 


\title{
Resumen
}

Este artículo pretende ofrecer una panorámica suficientemente representativa del interés que Cervantes y el Quijote han suscitado en diferentes escritores, filólogos y traductores mallorquines desde mediados del siglo XIX hasta hoy. La descripción abarca dos perspectivas: la crítica, centrada en la recepción del Quijote o en la figura de su creador, y la traductológica, enfocada hacia el análisis de las versiones mallorquinas del Quijote. En ambas, los cervantistas mallorquines han sabido mantener su propia voz en el concierto general hispano. Respecto a la primera, inclinándose por soluciones conciliadoras en polémicas y diatribas. Y, en cuanto a la segunda, optando por una peculiar manera de traducir el Quijote adaptándolo a la lengua autóctona hasta extremos insólitos en comparación con el resto de las versiones al catalán.

Palabras clave: cervantismo, cervantistas, Quijote, traducción, mallorquín.

\begin{abstract}
This article seeks to provide a representative overview of the interest that Cervantes and Don Quixote have sparked in various Majorcan writers, scholars and translators from the mid-nineteenth century to the present. The descriptive perspective is twofold, the first dealing with criticism in connection with the reception of Don Quixote and its author, and the second focusing on translation issues stemming from an analysis of the Majorcan versions of Don Quixote. In both regards, Majorcan specialists in Cervantes have succeeded in preserving their own voice within the larger Hispanic concert-in the first instance, leaning toward reconciliation amid polemic and diatribe, and in the second, opting for a peculiar approach to translating Don Quixote that adapts it to the autochthonous language in a way that proves extremely uncanny when compared with other Catalan renderings.
\end{abstract}

Key words: Cervantism, Cervantists, Don Quixote, translation, Majorcan. 